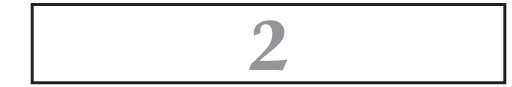

\title{
A PROPRIEDADE DO PETRÓLEO NO BRASIL
}

\subsection{CONSIDERAÇÕES GERAIS SOBRE O EXERCÍCIO DO DIREITO DE PROPRIEDADE PELO ESTADO: BENS DO DOMÍNIO PÚBLICO E DO DOMÍNIO PRIVADO}

Há muito, os administrativistas têm se dedicado à análise do regime jurídico que regula a relação de direito real entre o Estado e uma série de bens que lhe foram atribuídos pelo ordenamento jurídico, essenciais para o perfeito exercício de suas funçōes.

Fala-se em um domínio público e um domínio privado do Estado. No primeiro, estariam os bens de propriedade deste ente regidos por um regime jurídico de direito público, afetados ao uso direto ou indireto da coletividade, marcados pelos aspectos da inalienabilidade, imprescritibilidade, impenhorabilidade e impossibilidade de oneração.

Por sua vez, os bens do domínio privado do Estado seriam aqueles que, embora possam ser alvo de regulação específica por normas aplicáveis exclusivamente aos bens pertencentes ao ente público, subsidiariamente são regidos pelo direito privado, da mesma forma que os demais bens sob titularidade dos particulares.

Maria Sylvia Zanella Di Pietro, ao analisar a expressão domínio público, entende ser ela equívoca, uma vez que admite diversos significados. A autora menciona três deles que são de uso corrente pela doutrina:

1. em sentido muito amplo, a expressão domínio público é utilizada para designar o conjunto de bens pertencentes às pessoas jurídicas de direito público interno, políticas e administrativas (União, Estados, Municípios, Distrito Federal, Territórios e autarquias); 
2. em sentido menos amplo, utilizado na referida classificação do direito francês, designa os bens afetados a um fim público, os quais, no direito brasileiro, compreendem os de uso comum do povo e os de uso especial;

3. em sentido estrito, fala-se em bens do domínio público para designar apenas os destinados ao uso comum do povo, correspondendo ao domínio do direito italiano; como não eram considerados, por alguns autores, como pertencentes ao poder público, dizia-se que estavam no domínio público; o seu titular seria, na realidade, o povo (2011, p. 673-674).

Di Pietro adota a segunda definição, pois para ela tais bens guardam uma relação de propriedade pública com o Estado, tal qual defendido por Maurice Hauriou, portando, em essência, as mesmas características da propriedade priva$\mathrm{da}$, distinguindo-se desta somente pelo aspecto da afetação, que lhes imprime características particulares. Manuel Maria Diez (1969) refere-se aos bens do domínio público como sendo aqueles regidos por um regime jurídico de direito administrativo, submetidos ao princípio da inalienabilidade e imprescritibilidade, contendo regras diversas quanto à limitação do seu uso, proteção atribuída pelo direito penal, dentre uma série de outras regras específicas desconhecidas pelo direito privado. Da mesma forma como exposto por Di Pietro, para este autor tais bens relacionam-se com o Estado segundo um direito de propriedade pública, ou administrativa, cujo regime difere sensivelmente daqueles de propriedade privada. Observa que somente a noção de propriedade pública aplicada aos bens de domínio público explica satisfatoriamente uma série de consequências admitidas pela doutrina e jurisprudência.

Ainda com relação aos bens do domínio público, Diez afirma que "são aqueles bens de propriedade do Estado (lato sensu), afetados por lei ao uso direto ou indireto dos seus habitantes" (1969, p. 358), podendo-se extrair de tal definição os quatro elementos que informam os bens do domínio público: o elemento subjetivo, objetivo, teleológico e normativo ou legal.

Ao abordar o elemento subjetivo, o autor afirma ser indispensável, para que um bem se caracterize como pertencente ao domínio público, dentre outros requisitos, que forme parte do patrimônio de uma pessoa jurídica de direito público. Disso se extrai, por exemplo, que "se o Estado toma em locação um imóvel privado para o funcionamento de um serviço público, este bem não forma parte do domínio público" (1969, p. 360).

No que toca ao aspecto objetivo, deve haver um conjunto de bens determináveis em um dado momento, sendo cada um deles regidos pelo regime específico que a lei lhe houver atribuído segundo as suas características: bens corpóreos ou incorpóreos, móveis ou imóveis, principais ou acessórios etc. 
O elemento teleológico ou finalista, talvez o mais importante deles, segundo o autor, ao menos para fins de diferenciação dos bens públicos pertencentes ao domínio público daqueles bens públicos de domínio privado, fundamenta-se essencialmente na noção de afetação. Para Manuel Maria Diez, tem-se por afetação "o ato ou a declaração de vontade dos órgãos do Estado, em cujo mérito um bem é incorporado ao uso direto ou indireto da coletividade" (1969, p. 417).

Ana Raquel Gonçalvez Moniz, em obra intitulada $O$ critério e o regime jurídico da dominialidade, define afetação como:

Uma actuação administrativa dotada de relevância extrema na matéria que nos ocupa, constituindo verdadeiro instrumento da dinâmica do domínio público: repare-se que quando existe um acto de afectação, será o momento da sua prática o determinante para a aplicação a certa coisa do regime jurídico das coisas públicas; por outro lado, o destino a que a coisa é dotada pela afectação passará a reger também as respectivas possibilidades de uso. No fundo, a afectação consubstancia o acto administrativo que coloca a coisa (pública) a desempenhar a função que justificou a sua sujeição pelo legislador a um regime específico de direito público (o regime jurídico-administrativo da dominialidade pública); nessa medida, a afectação modifica sempre o estatuto jurídico da coisa, assumindo-se, nesta acepção, como um acto de criação das coisas públicas (2006, p. 138-139).

Além de tais elementos, Manuel Maria Diez refere-se ainda ao elemento normativo ou legal, segundo o qual "não existem bens públicos por natureza; somente a lei pode servir de fundamento para que um bem tenha o caráter de bem integrante do domínio público" (1969, p. 374). De todo modo, continua o autor, "os bens do domínio público podem estar estabelecidos pela lei, seja mediante uma indicação nominal específica dos mesmos ou mediante uma indicação genérica. Ademais, na falta de indicação genérica ou específica da lei, pode-se recorrer a uma interpretação analógica" (1969, p. 376).

Já os bens do domínio privado do Estado dizem respeito àqueles que pertencem ao Estado sob o mesmo título e as mesmas condições que a maior parte dos bens pertencentes aos particulares e estão regidos, fundamentalmente, pelas normas de direito privado. Como bem pontuado por Di Pietro:

Comparando os bens do domínio público com os do domínio privado do Estado, pode-se traçar a seguinte regra básica quanto ao regime jurídico a que se submetem: os primeiros, ao direito público, e, os segundos, no silêncio da lei, ao direito privado. O mesmo pensamento encontra-se em Ponte de Miranda (1954, v. 2:136): "na falta de regras jurídicas sobre os bens dominicais, incidem as de direito privado, ao passo que, na falta de regras jurídicas sobre bens públicos stricto sensu (os de uso comum e os de uso especial), são de atender-se os princípios gerais de direito público".

Se nenhuma lei houvesse estabelecido normas especiais sobre essa categoria de bens, seu regime jurídico seria o mesmo que decorre do Código Civil para os bens pertencentes aos particulares (2011, p. 679). 
Tais bens, por não estarem afetados ao uso direto ou indireto da coletividade, são passíveis de ser alienados ao particular, sujeitando-se, via de regra, às normas de direito privado. Como exposto pela autora citada anteriormente, isso não quer dizer que a disposição do Estado sobre os bens integrantes do seu domínio privado não possa sofrer limitações de ordem pública. A diferença destes para aqueles do domínio público é que, não estando afetados ao uso coletivo ou à Administração, podem ser alienados por meio de institutos do direito privado, tais como: compra e venda, doação, permuta, sujeitando-se subsidiariamente, no que couber, ao regime jurídico de direito privado.

No Brasil, adotou-se uma classificação própria para os bens públicos, tripartida, diferentemente do que ocorre no modelo estrangeiro, que se limita a classificar os bens públicos como pertencentes ao domínio público ou privado. O Código Civil de 2002, em seu artigo 99, classificou-os em: de uso comum do povo, especiais e dominicais. Embora peculiar ao nosso sistema, ao se analisar cada uma dessas classes de bens, percebe-se que as duas primeiras abarcam os bens integrantes daquilo que se apresenta como domínio público, enquanto os bens chamados pelo direito pátrio de dominicais correspondem à noção de bens do domínio privado.

\subsection{CLASSIFICAÇÃO DOS BENS PÚBLICOS NO DIREITO BRASILEIRO}

\subsubsection{Bens de uso comum do povo}

Àqueles bens integrantes do domínio público, disponíveis ao uso da comunidade sem distinção, seja por sua natureza ou por disposição legal, convencionou-se chamar, no direito brasileiro, de bens de uso comum do povo.

Faz-se a advertência de que bens do domínio público podem passar a integrar o domínio privado, por meio do instituto da desafetação, assim como bens do domínio privado podem vir a fazer parte do domínio público, por meio da afetação. Maria Sylvia Zanella Di Pietro elucida o tema ao expor que: "Pelos conceitos de afetação e desafetação, verifica-se que uma e outra podem ser expressas ou tácitas. Na primeira hipótese, decorrem de ato administrativo ou de lei; na segunda, resultam de atuação direta da Administração, sem manifestação expressa de sua vontade, ou de fato da natureza. Por exemplo, a Administração pode baixar decreto estabelecendo que determinado imóvel, integrado na categoria dos bens dominicais, será destinado à instalação de uma escola; ou pode simplesmente instalar essa escola no prédio, sem qualquer declaração expressa. Em um e outro caso, o bem está afetado ao uso especial da Administração, passando a integrar a categoria de bem de uso especial. A operação inversa também pode ocorrer, mediante declaração expressa ou pela simples desocupação do imóvel, que fica sem destinação" (2011, p. 677). 
Segundo definição proposta por Maria Sylvia Z. Di Pietro, bens comuns do povo são aqueles que, "por determinação legal ou por sua própria natureza, podem ser utilizados por todos em igualdade de condições, sem necessidade de consentimento individualizado por parte da Administração" (2011, p. 675)

O Código Civil de 2002 dispôs sobre tais bens em seu artigo 99, I, definindo-os de maneira exemplificativa como sendo aqueles destinados ao uso indistinto de todos, tais como "rios, mares, estradas, ruas e praças".

Celso Antônio Bandeira de Melo apresenta também definição denotativa, elencando, exemplificativamente, bens que compõem essa classe, a saber: "os de uso comum são os destinados ao uso indistinto de todos, como os mares, ruas, estradas, praças etc." (2007, p. 898).

Seu uso, em regra, caracteriza-se pelos princípios da liberdade e igualdade de acesso a toda a comunidade, gratuidade e tolerância mútua. Este último aspecto, que em substância identifica-se com o princípio da liberdade de acesso, foi concebido pela doutrina alemã, e, segundo Ana Raquel Gonçalvez Moniz, informa que "o exercício concreto do uso comum por um determinado sujeito não prejudica, impede ou exclui o uso comum pelos demais sujeitos" (2006, p. 449). Tal característica revela-se de sobranceira importância, notadamente por ser fator determinante na diferenciação dos bens de uso comum do povo daqueles que serão analisados adiante (bens de uso especial). Embora em ambas as classes haja bens integrantes do domínio público, estando presente tanto em um como em outro uma finalidade pública, a utilização de um bem de uso comum do povo por qualquer pessoa não exclui a possibilidade de outra vir, no mesmo momento, a utilizá-lo. Assim, por exemplo, a ida a uma praia, praça ou parque por alguém não impede que outro o faça, simultaneamente. Por outro lado, a utilização de um box em mercado público por particular, ou a destinação de um prédio para o funcionamento de um serviço público, exclui a possibilidade de outro gozar do mesmo benefício.

Por fim, cabe destacar, como bem lembra Edmir Netto de Araújo, que o princípio da gratuidade está sujeito a mitigaçôes, podendo o uso de um bem comum do povo se achar sujeito ao pagamento de um preço. Neste caso, ter-se-ia o que o autor chamou de uso comum extraordinário (enquanto o uso não remunerado seria considerado uso comum ordinário), em que, "embora abertos os bens à utilização de todos, a lei a faz depender do atendimento de certas condições, seja título jurídico (autorização, licença etc.) ou remuneração (pedágio, bilhetes de entrada, p. ex.)" (2010, p. 1.149), justificando-se tal cobrança em face do interesse coletivo na preservação do bem. 


\subsubsection{Bens de uso especial}

Os bens de uso especial foram definidos no inciso II do artigo 99 do Código Civil como sendo aqueles "destinados a serviços ou estabelecimento da administração federal, estadual, territorial ou municipal, inclusive os de suas autarquias".

Segundo Bandeira de Melo, são aqueles "afetados a um serviço ou estabelecimento público, como as repartições públicas, isto é, locais onde se realiza a atividade pública ou onde está à disposição dos administrados um serviço público, como teatros, universidades, museus" (2007, p. 898).

Di Pietro critica a expressão "uso especial", utilizada para designar essa modalidade de bem, pois ela se confundiria com outro sentido em que é utilizada, tanto no direito estrangeiro como no direito brasileiro, "para indicar o uso privativo de bem público por particular e também para abranger determinada modalidade de uso comum sujeito a maiores restriçôes, como pagamento de pedágio e autorização para circulação de veículos especiais" (2011, p. 675).

Diante de tais considerações, entende a autora ser mais adequada a expressão utilizada pelo direito italiano e pelo antigo Código de Contabilidade Pública, qual seja: bens do patrimônio indisponível. Nesta se ressalta "o caráter patrimonial do bem (ou seja, a sua possibilidade de ser economicamente avaliado) e a sua indisponibilidade, que resulta, não da natureza do bem, mas do fato de estar ele afetado a um fim público" (2011, p. 675).

Entende-se, no entanto, que a possibilidade de avaliação econômica do bem, mencionada pela autora, pode estar presente também nos bens públicos de uso comum do povo, por exemplo, uma praça ao ser desafetada pode ser alienada a um particular que deseja construir no local um clube privado, com finalidade lucrativa. Por isso, conforme exposto no tópico anterior, é a exclusividade na utilização do bem público, seja por uma pessoa ou por um grupo determinado de pessoas, adstrita a uma finalidade pública predeterminada pela lei, que atribui nota característica a essa classe de bens (afetação), diferenciando-a daquela que abarca os de uso comum do povo, também afetados a uma finalidade pública.

\subsubsection{Bens dominicais}

Os bens dominicais, ou dominiais, por sua vez, encontram-se regulados no artigo 99, III, do Código Civil, nos seguintes termos:

Art. 99. São bens públicos:

\section{(...)}

III - os dominicais, que constituem o patrimônio das pessoas jurídicas de direito público, como objeto de direito pessoal, ou real, de cada uma dessas entidades. 
Parágrafo único: Não dispondo a lei em contrário, consideram-se dominicais os bens pertencentes às pessoas jurídicas de direito público a que se tenha dado estrutura de direito privado.

Conforme aduz Celso Antônio Bandeira de Melo (2007, p. 898), têm-se por bens dominicais, também chamados de dominiais, aqueles que:

são os próprios do Estado como objeto de direito real, não aplicados nem ao uso comum, nem ao uso especial, tais os terrenos ou terras em geral, sobre os quais tem senhoria, à moda de qualquer proprietário, ou que, do mesmo modo, lhe assistam em conta de direito pessoal. O parágrafo único do citado artigo pretendeu dizer que serão considerados dominicais os bens das pessoas da Administração indireta que tenham estrutura de direito privado, salvo se a lei dispuser em contrário.

Como bem pontuado pelo autor em sua definição, são aspectos que conformam essa classe de bens: 1) integram o patrimônio disponível da administração, 2) não estão afetados ao uso direto ou indireto da coletividade ou da própria administração, 3) podem ser alienados, mediante autorização legal. São aqueles que, no direito brasileiro, integram o domínio privado dos bens públicos, examinados anteriormente.

De maneira geral, destinam-se à obtenção de renda pelo Estado, seja por meio da sua alienação, seja por meio da remuneração obtida em face do seu uso por um particular. No entanto, como bem ensina Di Pietro (2011), a natureza patrimonial desses bens não é uma característica essencial, pois sua administração pode visar, também, a consecução de objetivos de interesse geral.

Com efeito, os bens do domínio privado são frequentemente utilizados como sede de obras públicas e também cedidos a particulares para fins de utilidade pública. Por exemplo, no direito brasileiro, é prevista a concessão de direito real de uso para fins de urbanização, industrialização, cultivo e também a sua cessão, gratuita ou onerosa, para fins culturais, recreativos, esportivos. E mesmo quando esses bens não são utilizados por terceiros ou diretamente pela Administração, podem ser administrados no benefício de todos, como as terras públicas onde se situem florestas, mananciais ou recursos naturais de preservação permanente.

Além disso, a própria administração financeira constitui objetivo apenas imediato, pois, em uma perspectiva mais ampla, atende a fins de interesse geral (2011, p. 679).

Essa nova forma de se encarar a natureza e a função dos bens dominicais, prossegue a autora em sua explanação, leva inclusive alguns autores a considerar a sua administração como serviço público sob regime de gestão privada, de modo que esse duplo aspecto dos bens dominicais justificaria a sua submissão a regime jurídico de direito privado parcialmente derrogado pelo direito público.

Esta última consideração feita pela autora é de suma importância, uma vez que, de fato, não há que se falar em bens dominiais integralmente regidos por um 
regime de direito privado, como inclusive pontuado ao tratar do domínio privado do Estado, oportunidade em que se enfatizou estarem apenas subsidiariamente, na ausência de regulação específica, sujeitos ao regime geral dos bens privados. Não é porque sejam passíveis de disposição que deixam de cumprir finalidades públicas, podendo o Estado regular o seu uso, mesmo quando feito pelo particular, com vistas a atender a objetivos de interesse coletivo. Além disso, é possível que a imposição de uma limitação ao seu uso permaneça sobre tais bens mesmo após alienados ao particular, conforme será visto adiante, no caso da alienação do petróleo.

Enfim, pelo fato de não estarem afetados ao uso direto, seja pela Administração Pública, coletividade, pessoa ou grupo específico, podem ser alienados, sendo precisamente esta (a alienabilidade) a característica que os diferencia dos bens de uso comum do povo e de uso especial, e não a existência de uma finalidade pública, porquanto esta, em menor ou maior grau, estará sempre presente em todos eles.

\subsection{DO REGIME JURÍDICO APLICÁVEL AO PETRÓLEO COMO BEM PÚBLICO NO DIREITO BRASILEIRO}

\subsubsection{Definições técnicas importantes}

Antes de proceder à análise do tema em epígrafe (Do Regime Jurídico Aplicável ao Petróleo como Bem Público no Direito Brasileiro), faz-se mister discorrer sobre o conteúdo de expressóes peculiares à indústria do petróleo, incorporadas pela legislação, tais como: jazidas, depósitos, campos e blocos, as quais se referem a diferentes estágios por que passa essa substância em seu processo de produção. Até mesmo o termo petróleo merece ser mais bem compreendido, tendo em vista que, por diversas vezes, aplicam-se regras específicas segundo o estado em que este é encontrado na natureza, sendo essencial, portanto, precisar a forma como a legislação pátria define cada um desses termos, sob pena de se atribuir o mesmo significado a situações jurídicas distintas.

Tais conceitos encontram-se definidos na legislação brasileira, seguindo, de maneira geral, as definiçôes propostas em conjunto pela Society of Petroleum Engineers (SPE), American Association of Petroleum Geologists (AAPG), World Petroleum Council (WPC), Society of Petroleum Evaluation Engineers (SPEE) e Society of Exploration Geophysicists (SEG), por meio da publicação intitulada "Guidelines for Application of the Petroleum Resources Management System", cuja edição mais recente data de novembro de 2011, além daquelas propostas pela United States Securities and Exchange Comission (SEC), entidade vinculada ao governo federal dos Estados Unidos, cuja finalidade é regular o mercado de títulos 
naquele país, destinando-se todas essas organizações a compilar as melhores práticas adotadas pela indústria internacional do petróleo. ${ }^{8}$

\subsubsection{O que é o petróleo?}

Segundo a SPE et al., o termo petróleo refere-se a "um composto natural de hidrocarbonetos em estado gasoso, líquido ou sólido” (2011, p. 209, tradução nossa). Para Williams e Meyers, "petróleo é o nome genérico que se dá para compostos de hidrocarbonetos combustíveis encontrados na terra” (2008, p. 3, tradução nossa). De acordo com os autores, a estrutura molecular desse composto de hidrogênio e carbono pode variar desde uma simples estrutura de metano (CH4), componente do gás natural combustível, até estruturas mais complexas, como é a do octano (C8H18), um componente do óleo cru. Além disso, impurezas estão frequentemente associadas ao petróleo (o composto de enxofre que contamina o gás ácido e o óleo), devendo ser removidas antes da sua comercialização.

Destacam que entre as várias propriedades físicas do petróleo estudadas, três são fundamentais para a compreensão do seu processo de produção e das diferenças de preços atribuídas no mercado aos diversos tipos de petróleo produzidos. Primeiramente, tem-se que o petróleo pode aparecer na natureza em estado gasoso, líquido e sólido, mais comumente como gás ou líquido (quando aparece no estado líquido, está quase sempre associado ao gás na sua composição). Outra importante propriedade é a sua gravidade específica ou densidade. O petróleo líquido normalmente é mais leve que a água, que possui densidade 1 (por exemplo, a densidade do octano é de 0,7064). No entanto, na indústria do petróleo, a densidade é comumente expressa em graus de A.P.I., adotando-se, nesta escala, uma razão invertida,

\footnotetext{
Em diversas passagens, a legislação brasileira impõe às empresas que atuam na indústria do petróleo no Brasil a observância das melhores práticas adotadas internacionalmente para esse setor, dentre os quais destacamos os artigos $8^{\circ}$ e 44 :

Art. $8^{\circ}$ A ANP terá como finalidade promover a regulação, a contratação e a fiscalização das atividades econômicas integrantes da indústria do petróleo, do gás natural e dos biocombustíveis, cabendo-lhe:

(...)

IX - fazer cumprir as boas práticas de conservação e uso racional do petróleo, gás natural, seus derivados e biocombustíveis e de preservação do meio ambiente;

Art. 44. O contrato estabelecerá que o concessionário estará obrigado a: (...) VI - adotar as melhores práticas da indústria internacional do petróleo e obedecer às normas e procedimentos técnicos e científicos pertinentes, inclusive quanto às técnicas apropriadas de recuperação, objetivando a racionalização da produção e o controle do declínio das reservas (Lei n. 9.478/97).
} 
de modo que o petróleo com a menor densidade possui um maior grau A.P.I. (a maioria dos tipos de óleos crus existentes possui entre 27 e $35^{\circ}$ graus A.P.I.). Quanto maior o valor em A.P.I., maior será o preço alcançado pelo óleo. Uma terceira propriedade a ser destacada é a sua viscosidade. Quanto menor a viscosidade do fluido, maior será sua mobilidade, e maior o seu valor no mercado.

Em estudo formulado pela Royal Dutch/Shell Group of Companies (1983), explica-se que a expressão petróleo costuma ser utilizada em dois sentidos, um mais amplo e outro mais estrito. Naquele, refere-se a todos os hidrocarbonetos que aparecem sobre a terra, ao passo que, em sentido mais restrito, utilizado com maior frequência para fins comerciais, consiste apenas nos depósitos líquidos de óleo cru, enquanto a sua forma gasosa é chamada de gás natural, e os sólidos de betume ou asfalto, sendo os dois primeiros as principais substâncias utilizadas na indústria.

Do exposto, conclui-se que 1) o petróleo é um composto orgânico, 2) entendido como sinônimo de hidrocarbonetos combustíveis em um sentido amplo, aparecendo na natureza em estado sólido, líquido ou gasoso, ou, em um sentido mais estrito, como sinônimo de óleo cru ou petróleo em estado líquido.

$\mathrm{Na}$ legislação brasileira, o petróleo é considerado, ao lado do gás natural, uma espécie de hidrocarboneto, tendo sido adotada, portanto, uma definição mais restrita para o termo. Tal afirmação pode ser extraída mediante a análise do artigo $6^{\circ}$ da Lei n. 9.478/97,9 em consonância com o disposto no artigo 177, I, da Constituição Federal, segundo o qual constituem monopólio da Uniāo "a pesquisa e a lavra das jazidas de petróleo e gás natural e outros hidrocarbonetos fluidos”.

No entanto, no presente estudo, opta-se por utilizar a expressão "petróleo" para se referir a todos os hidrocarbonetos fluidos (utilizando tais expressóes como sinônimos, portanto), fazendo a distinção apenas quando um tipo específico de hidrocarboneto fluido receba tratamento jurídico diverso.

É importante mencionar, ainda, a imprecisão terminológica incorrida pelo legislador constituinte ao regular a propriedade do petróleo no artigo 20 da CF, considerando-o um bem integrante do patrimônio da União. No inciso IX do referido artigo, afirma-se que são bens da União "os recursos minerais, inclusive os do subsolo". Tal dispositivo é tido como o fundamento constitucional da propriedade

Art. $6^{\circ}$ Para os fins desta Lei e de sua regulamentação ficam estabelecidas as seguintes definiçóes: I - Petróleo: todo e qualquer hidrocarboneto líquido em seu estado natural, a exemplo do óleo cru e condensado; II - Gás Natural ou Gás: todo hidrocarboneto que permaneça em estado gasoso nas condições atmosféricas normais, extraído diretamente a partir de reservatórios petrolíferos ou gaseíferos, incluindo gases úmidos, secos, residuais e gases raros; (Lei n. 9.478/97). 
da União sobre o petróleo existente no subsolo terrestre, uma vez que com relação ao subsolo marinho, cuidou o inciso $\mathrm{V}$ do mesmo artigo ao afirmar que são bens da União os recursos naturais da plataforma continental. O fato é que, em uma interpretação puramente gramatical do inciso IX, pode-se concluir que a Constituição Federal não regulou a propriedade do petróleo presente no subsolo terrestre, uma vez que petróleo não é recurso mineral, mas sim um composto orgânico, conforme elucidado anteriormente.

Questão semelhante foi enfrentada nos Estados Unidos, estado do Texas, em 1901, conforme relata notícia do New York Times de 24 de abril desse ano, ${ }^{10}$ No caso, uma empresa desejava forçar o estado do Texas a lhe vender uma área pertencente ao Fundo Escolar Estadual, localizada sobre um campo de petróleo, conforme permitia a legislação da época, ${ }^{11}$ sob o argumento de que o petróleo era tratado como minério pela legislação estadual, e portanto, sujeito ao regime jurídico aplicado para as minas em geral. O Comissário de Terras do estado do Texas apresentou defesa

10 Is petroleum a mineral? An interesting suit is now engaging the attention of Texas jurists which involves a new question and, one which the geologists will have to take a hand in settling. The law of the state makes certain provisions for the sale of lands, which are the property of the Commonwealth to anyone who shall locate thereon a claim to mineral in the ground.

Under this provision an enterprising speculator has brought suit in the Supreme Court to compel the state land Commissioner to sell him a section of land in the heart of Beaumont oil field belonging to the State School Fund, on the ground that it is mineral land within the meaning of the statute, and subject to location as such.

The question which this suit raises is whether petroleum is a mineral at all. Its name identifies it with the rocks of what are known as the oil measures, but it is by no means clear that is a mineral product. Indeed, a consensus of expert opinion would probably class it as an animal oil, expressed from the carcases of the fishes, saurians and amphibians of the early world. (...) At no stage of the process, however, did it become a mineral, remaining what it was at the outset, a hydrocarbon of unmistakably organic origin. (...) This fact, which we believe is not considered open to dispute by geologists, would seen to afford a slender basis for a suit to compel the Texas authorities to open the oil-bearing school lands to location as mineral lands. Whether it would not be of advantage to the school fund to convert these lands into money at this time, is quite another question, and one which the facts at our command do not warrant us in discussing. That the state land commissioner is defending the suit would seen to indicate that he thinks the interest of the state would best be served by not selling the land in question, or else that he lacks the power to do so under the claim that petroleum imparts to the area yielding it the character of mineral land in the meaning of the statute (NEW YORK TIMES, 1901).

11 Following a kind of expropriation procedure, laws of 1880's and 1890's in most states gave miners the rights to enter strictly private lands to prospect for and recover the mineral beneath. (Depending on the state, the surface owner received compensation for damage to his property or a royalty)". In USA, "the free access to public lands implied two policies: tolerance of racing behaviour and procedural openness" (SCOTT, 2008, p. 260). 
alegando que, além de não haver interesse do Estado, o petróleo não seria uma substância mineral, estando sujeita a regime diverso.

Contudo, conforme bem se posicionou o Supremo Tribunal Federal, no voto do Ministro Carlos Brito na ADIn 3.273-9/DF:

A Carta-cidadā, fiel à proposição kelseniana de que o Direito constrói suas próprias realidades, optou por ignorar as discussões geológicas e geofísicas sobre a distinção entre hidrocarbonetos fluidos e gasosos (que seriam substâncias orgânicas) e os recursos minerais propriamente ditos. Isto para fazer destes últimos (recursos minerais) o gênero no qual os dois primeiros recursos naturais se encartariam. As duas tipologias fundindo-se, a princípio, numa única realidade normativa ou figura de Direito, sob o nome abrangente de recursos naturais.

Louvável o entendimento, e, mesmo se assim não fosse, o inciso I do artigo 20 da Constituição Federal previu que são também bens da União aqueles que vierem a ser atribuídos por Lei Ordinária, o que é feito por meio da Lei n. 9.478/97. Não obstante, aplaude-se o argumento posto pelo STF, entendendo que a propriedade do petróleo encontrado na porção terrestre do território é atribuída, por força constitucional, à União, não apenas por dispositivo de Lei Ordinária.

\subsubsection{Outras definições importantes: reservatórios, jazidas, blocos e campos}

Embora contenham definição jurídica distinta, é comum que se confundam expressões como jazidas, blocos, campos, depósitos e poços, motivo por que serão analisadas uma a uma.

Acumulações de petróleo são encontradas na natureza em reservatórios naturais formados em bacias sedimentares na crosta terrestre. Enquanto não identificadas, tais acumulações constituem-se simplesmente em reservatórios ou depósitos, definidos pela Lei do Petróleo ${ }^{12}$ como "configuração geológica dotada de propriedades específicas, armazenadora de petróleo ou gás, associados ou não” (art. 6º X).

Para que tais depósitos venham a ser identificados, faz-se necessária uma série de estudos geológicos e geofísicos, postos em prática por empresa contratada para explorar e produzir petróleo, o que pode se dar no Brasil por meio de contrato de concessão ou de partilha da produção. Tais depósitos podem vir a se constituir em jazidas, ${ }^{13}$ o que só ocorre no exato momento em que são descobertos pelo contratado e tidos por este como possivel de ser posto em produção. Ou seja, não é qualquer

12 Chama-se de Lei do Petróleo a Lei n. 9.478/97.

13 Lei n. 9.478/97: art. 60 (...) "XI - Jazida: reservatório ou depósito já identificado e possível de ser posto em produção"; 
depósito de petróleo que pode se tornar uma jazida, mas somente aqueles em que se vislumbra a possibilidade de se extrair petróleo, o que pode não ocorrer, caso a sua produção não se mostre economicamente viável, por não haver conhecimento técnico suficiente, ou qualquer outro motivo que inviabilize sua extração. De todo modo, uma vez identificada uma jazida pelo contratado, tem este o dever de comunicar imediatamente tal fato à Agência Nacional do Petróleo (Lei n. 9.478/97, art. 44, II). Não havendo interesse em continuar seus trabalhos exploratórios para fins de identificação de jazidas, poderá exercer sua opção de desistência e de devolução das áreas em que, a seu critério, não se justifiquem investimentos em desenvolvimento (Lei n. 9.478/97, art. 28, V).

Vista a diferença entre depósitos e jazidas, menciona-se em que consiste o termo bloco. Sua definição consta no inciso XIII, artigo $6^{\circ}$ da Lei n. 9.478/97, segundo o qual representa a "parte de uma bacia sedimentar, formada por um prisma vertical de profundidade indeterminada, com superfície poligonal definida pelas coordenadas geográficas de seus vértices, onde são desenvolvidas atividades de exploração ou produção de petróleo e gás natural". De maneira mais simples, consiste na área posta para licitação, em que pode estar contida uma ou mais jazidas, ou mesmo parcela destas, isto é, pode ocorrer que uma única jazida se estenda por dois ou mais blocos, concedidos a empresas petrolíferas distintas, ocasião em que precisarão firmar um acordo de individualização da produção.

A delimitação dos blocos a serem objeto de contrato de concessão ou de partilha de produção é de competência do Conselho Nacional de Política Energética - CNPE (Lei n. 9.478/97, art. 2, VIII), que, para tanto, tomará por base os estudos promovidos pela ANP, nos termos do artigo $8^{\circ}$, II, dessa mesma norma.

$\mathrm{Na}$ fase de exploração, os contratados estão obrigados a cumprir os investimentos e programas exploratórios mínimos especificados no contrato, conforme definido no artigo 37, I, da Lei do Petróleo. Isso envolve, além da utilização de dados de sísmica, a perfuração de um número mínimo de poços exploratórios, conforme explica Decio H. Barbosa:

$\mathrm{Na}$ fase exploratória são realizados estudos de sísmica para identificar possíveis acumulações de hidrocarbonetos no subsolo (prospectos). Uma vez obtidos e analisados os dados técnicos, toma-se a decisão de seguir ou não adiante com o projeto. Se a decisão for seguir adiante, o próximo passo é perfurar um poço exploratório. Se o poço não for bem sucedido, o projeto tem grandes chances de ser abandonado. Se, por outro lado, forem encontrados hidrocarbonetos, a companhia tem outra decisão a tomar: testar (ou não) se a acumulação de hidrocarbonetos é comercial (2011, p. 14).

Em caso de êxito na exploração, após descoberto um reservatório tido como possível de ser posto em produção (jazida), ensina Decio $\mathrm{H}$. Barbosa que há de se 
certificar acerca das suas características (tamanho, estrutura e qualidade), reduzindo destarte as incertezas de natureza técnica. "Se os poços exploratórios perfurados identificarem a presença de razoáveis quantidades de óleo ou gás, são perfurados poços de avaliação para definir o tamanho e a extensão do campo" (2011, p. 14). No entanto, destaca que incertezas ainda estão presentes nesta fase, uma vez que "pode não haver quantidade suficiente de óleo ou gás que justifique a comercialização ou a tecnologia necessária à produção, por ser muito onerosa” (2011, p. 14). De todo modo, uma vez confirmada a viabilidade comercial da jazida, tem início a fase de desenvolvimento, na qual o contratado deverá submeter à ANP seus planos e projetos de desenvolvimento e produção, devendo esta entidade emitir parecer sobre estes no prazo de 180 dias, considerando-se tais planos aprovados automaticamente caso não haja manifestação dentro do prazo estipulado pela legislação (Lei n. 9.478/97, art. 26, $\$ \$ 1^{\circ}$ a $3^{\circ}$ ). Uma vez aprovados expressa ou tacitamente, o contratado está autorizado a dar início à fase de produção, ocasião em que são perfurados os primeiros poços produtores ou completados aqueles já existentes, conectando-os à unidade de produção e esta aos dutos de exportação da produção, a fim de que se produzam óleo e gás. Somente a partir daí é que se pode falar na existência de um campo de óleo bruto ou gás natural, definido pela legislação como "área produtora de petróleo ou gás natural, a partir de um reservatório contínuo ou de mais de um reservatório, a profundidades variáveis, abrangendo instalações e equipamentos destinados à produção" (Lei n. 9.478/97, art. 6 XIV).

Por fim, entende-se ser relevante a elucidação de outros conceitos que, apesar de não constarem expressamente na Lei do Petróleo, são de uso corrente na indústria internacional do petróleo, quais sejam o de reservas possíveis, prováveis e provadas, em desenvolvimento ou não. Tais expressões foram criadas pela SPE e SEC com a finalidade de uniformizar a apuração do número de reservas de petróleo pelas empresas, consideradas como os principais ativos constantes no seu balanço patrimonial, tornando esses dados comparáveis entre si. A observância de tais normas pelas empresas faz-se necessária, uma vez que para negociarem suas ações na Bolsa de Nova Iorque, precisam classificar suas reservas em conformidade com as regras da SEC. As empresas que negociam seus títulos na Bovespa estão sujeitas às regras da Comissão de Valores Mobiliários, conforme ensinam Moreira et al., entidade esta que se baseia nas regras formuladas pela SPE.

O termo reserva, utilizado por tais entidades, equivale de maneira geral ao que o direito brasileiro chama de jazida. Tem-se uma reserva como provada quando nela houver quantidades de petróleo, que por análises da geologia e dados da engenharia, podem ser estimadas com uma razoável certeza de ser comercialmente 
recuperadas, sob condições econômicas atuais, métodos operacionais e regulamentações governamentais, podendo ser classificadas em reservas provadas desenvolvidas e não desenvolvidas. Reservas desenvolvidas seriam aquelas em que o petróleo pode ser recuperado através de poços existentes e quando todos os equipamentos necessários à produção encontram-se instalados.

As reservas consideradas como não provadas dividem-se em prováveis e possíveis. Aquelas são as reservas cujas análises de geologia e dados de engenharia sugerem que haja maior probabilidade de serem recuperadas do que estas. Neste contexto, quando métodos probabilísticos são usados, as reservas prováveis devem ter ao menos $50 \%$ de probabilidade de ser postas em produção, enquanto as possíveis representam uma probabilidade de 10 a 50\% (SPE, 2011).

\subsubsection{Da propriedade do petróleo no direito brasileiro}

Ensina Di Pietro que no período colonial e durante o regime das Ordenações Filipinas, "a propriedade das jazidas era da Coroa; a sua exploração era feita pelo regime regaliano, devendo o concessionário pagar o quinto” (2011, p. 733).

Com a independência, continua a autora, "a Lei de 20 de outubro de 1823 mandou que se aplicassem no Brasil as leis portuguesas, de modo que o regime continuou o mesmo, pertencendo as minas à Nação" (2011, p. 733).

A Constituição Republicana de 1891, elaborada sob uma concepção individualista, não fazia distinção entre propriedade do solo e dos recursos minerais nele contidos. Ensina Pontes de Miranda que no sistema desta Constituição, antes da Lei n. 4.625, de 15 de janeiro de 1921, "a propriedade das jazidas minerais ou, melhor, das minas - era, como a de produtos orgânicos, direito incluído no de domínio. A mina era, portanto, parte integrante essencial” (1954, t. II, p. 99).

Com isso, não havia distinção entre propriedade do solo/subsolo e das jazidas de minerais porventura existentes, podendo o proprietário do solo explorar os recursos minerais contidos no subsolo de sua propriedade da maneira que lhe conviesse, sem nada dever ao Estado por isso. Eis o que dizia a respeito o artigo 72, parágrafo 17, da referida Constituição.

Os direitos de propriedade mantêm-se em toda sua plenitude, salvo a desapropriação por necessidade ou utilidade pública, mediante indenização prévia. As minas pertencem ao proprietário do solo, salvo as limitaçôes que forem estabelecidas a bem da exploração deste ramo da indústria.

Em consonância com esse sistema, conforme dispõe Di Pietro, o artigo 526 do Código Civil de 1916 "veio determinar que a propriedade do solo abrange a do que 
lhe está superior e inferior em toda a altura e em toda profundidade, úteis ao seu exercício, só podendo, todavia, o proprietário opor-se a trabalhos que sejam empreendidos a uma altura ou profundidade tais que não tenha interesse algum em impedi-los" (2011, p. 733).

Progressivamente, a legislação foi incorporando restrições a esse direito ilimitado do proprietário sobre as riquezas minerais do subsolo. A primeira delas surgiu, conforme ensina Pontes de Miranda, com a Lei n. 4.265, de 15 de janeiro de 1921, a qual, em seu artigo 50, "veio desessencializar como parte integrante do solo a mina. Passava essa a ser parte integrante não-essencial” (1954, t. II, p. 107). A partir daí voltou-se a diferenciar, no direito brasileiro, regime de propriedade do solo e dos recursos minerais, embora ambos ainda pertencessem ao proprietário do solo.

$\mathrm{Na}$ Constituição de 1934, o artigo 118 reforçou essa distinção, dispondo que "as minas e demais riquezas do subsolo, bem como as quedas d'água, constituem propriedade distinta da do solo para o efeito de exploração ou aproveitamento industrial". Além disso, importante limitação à propriedade foi introduzida no artigo 119, determinando que o aproveitamento industrial das minas e das jazidas minerais, bem como das águas e da energia hidráulica, ainda que de propriedade privada, não poderia mais ser feito livremente pelo proprietário e dependeria de autorização ou concessão federal prévia, na forma que a lei estipulasse. Apenas aquelas minas que já estivessem em lavra, ou as quedas d'água já utilizadas industrialmente na data da promulgação da Constituição, estariam dispensadas de tal formalidade (art. 119, $\$ 6^{\circ}$ ).

Tais limitações contidas na Constituição de 1934, e mantidas nos mesmos termos na Constituição de 1937, apenas impunham restrições ao exercício da propriedade das minas, que continuavam a pertencer ao proprietário do solo em sua inteireza. Sobre tal aspecto, foi enfático Pontes de Miranda ao afirmar que:

Ao estatuir que o aproveitamento das quedas de água já utilizadas industrialmente na data da sua promulgação não dependia de concessão ou de autorização, como também a "exploração das minas em lavra, ainda que transitoriamente suspensa", de modo nenhum se referia à propriedade: referia-se à atividade iniciante e fiscalizadora do Estado, ao princípio da autorização ou concessão da mina. Esse princípio limita o conteúdo do direito de propriedade (1954, t. II, p. 107, grifos nossos).

Sobre a publicização das minas, havia apenas a previsão em ambas as Constituições (CF de 1934, art. 119, $\$ 4^{\circ}$, e CF de 1937, art. 144) de que a "lei regulará a nacionalização progressiva das minas, jazidas minerais e quedas d'água ou outras fontes de energia hidráulica, julgadas básicas ou essenciais à defesa econômica ou militar do País”. No entanto, tal norma não chegou a ser editada, de modo que o regime de propriedade privada das jazidas permaneceu absoluto para qualquer tipo 
de recurso mineral (incluindo-se aí o petróleo) até a edição do Decreto-lei n. 366/38, que alterou o Código de Minas vigente à época (Decreto n. 24.642/34), momento em que as jazidas de petróleo passaram a compor o domínio privado da União ou dos Estados, segundo a sua localização, nos termos dos artigos 96 e 97:

Art. 96 A lei não reconhece o domínio privado de particulares, como já instituído, sôbre jazidas de petróleo e gases naturais, pelo fato de não ter sido descoberta nenhuma jazida desta classe suscetível de utilização industrial, enquanto vigorou o direito de acessão da propriedade do solo sôbre as minas.

Parágrafo único. Ficam de nenhum efeito os manifestos e registros de jazidas de petróleo e gases naturais que, porventura, hajam sido efetuados, com fraude da lei, na conformidade do art. 10 dêste Código.

Art. 97 As jazidas de petróleo e gases naturais acaso existentes no território nacional pertencem aos Estados ou a União, a título de domínio privado imprescritível, na seguinte conformidade:

a) pertencem aos Estados as que se acharem em terras do seu domínio privado, ou em terras que, tendo sido do seu domínio privado, foram alienadas com reserva expressa, ou tácita por fôrça de lei da propriedade mineral;

b) pertencem à União, em todos os demais casos.

Com relação aos demais recursos minerais, continuaram a integrar o patrimônio do proprietário do solo até a publicação do Código de Minas de 1940 (Decreto-lei n. 1.985/40), quando, por força do seu artigo 10, vieram a integrar o patrimônio da União.

Nas Constituições que se seguiram, apenas foi reiterada a distinção entre propriedade do solo/subsolo e das jazidas aí contidas, bem como os requisitos para o exercício das atividades de exploração e produção desses recursos, dependentes, conforme o caso, de autorização ou concessão federal. Além disso, a partir da Constituição de 1967, especificamente com relação ao petróleo, o exercício de tais atividades passou a ser monopólio da Uniāo, que por disposição constitucional, estava obrigada a atuar diretamente nos setores de exploração e produção de petróleo, mandamento este que permaneceu até a edição da Emenda à Constituição Federal de 1988, n. 9/95, pela qual a observância ao regime de monopólio deixou de ser uma imposição, tornando-se uma opção da União, que poderia contratar empresas públicas ou privadas para tal finalidade.

Com relação ao regramento do regime de propriedade dos recursos minerais e do petróleo, este passou a ser tratado em nível constitucional somente a partir da Constituição Federal de 1988, que em seu artigo 20 elencou-os dentre os bens pertencentes à União, conforme exposto na seção precedente. 


\subsubsection{Do petróleo como bem dominical}

\subsubsection{Exposição da controvérsia}

Após tais considerações, analisa-se em qual tipo de bem público se enquadra o petróleo: bem de uso comum do povo, de uso especial ou dominical?

Esse é um ponto que comporta certa discordância, não só por parte da doutrina, mas também pela jurisprudência, tendo sido objeto de discussão nos votos proferidos pelos Ministros do Supremo Tribunal Federal no julgamento da Ação Direta de Inconstitucionalidade 3.273-9/DF, cuja relatoria coube originariamente ao Ministro Carlos Brito. O cerne da questão discutida na ADIn referia-se ao regime constitucionalmente previsto para a regulação das atividades de exploração e produção de petróleo no Brasil, tendo como pano de fundo a análise do conteúdo da expressão monopólio, contida no artigo 177 da Constituição Federal, tema que será analisado em momento oportuno.

Por ora, expõe-se o debate travado na ocasião acerca da classificação do petróleo como bem público, se consistiria em um bem público de uso especial, posição defendida pelos Ministros Marco Aurélio e Carlos Brito, bem como, na doutrina, pelo Professor Gilberto Bercovici, ou se seria um bem público dominical, conforme argumentou Eros Grau, seguido pelos demais Ministros da Corte e por boa parte da doutrina, ${ }^{14}$ posição à qual este estudo se filia, segundo argumentos que se passa a expor, contrapondo-se àqueles apresentados no julgamento em favor da sua classificação como bem público de uso especial.

Antes, porém, cabe descartar a possibilidade de o petróleo figurar como bem público de uso comum do povo, hipótese defendida por Celso Antonio Pacheco Fiorillo e Renata Marques Ferreira, para quem este recurso possui natureza jurídica de bem ambiental. Aduzem os autores que:

O petróleo, como recurso ambiental que é, passa, a partir da Constituição Federal de 1988, a ter natureza jurídica de bem ambiental, a saber, é considerado um bem de uso comum do povo (...) a partir da Constituição Federal de 1988, ficou assegurado, nos termos da lei, aos Estados, ao Distrito Federal e aos Municípios, bem como aos órgãos da administração direta da União, participação no resultado da exploração de petróleo, nos termos do artigo 20, IX; (...) referida participação, sendo o petróleo bem de uso comum de todos, deve ser direcionada, não somente em proveito de parcela irrisória da população brasileira (apenas alguns poucos Estados e Municípios), mas, sim, em proveito de toda a população brasileira (2010, p. 200).

14 Neste sentido, entendem RIBEIRO, Carlos Luiz. Direito minerário escrito e aplicado; FREIRE, William. Código de mineração anotado; MARQUES NETO, Floriano Peixoto de Azevedo. Bens públicos: função social e exploração econômica. 
Tendo em vista que este bem não se destina ao uso indistinto de todos, como aqueles exemplificados na norma civil, mas somente àqueles que por meio de contrato com a União conseguiram obter o direito de se apropriar dele, após extraído, não há que se falar em uso comum do povo, por não se submeter aos princípios de igualdade e liberdade de acesso, gratuidade, muito menos, e principalmente, da tolerância, uma vez que a sua apropriação por um sujeito exclui a possibilidade do seu uso pelos demais. Uma coisa é a destinação da receita pública auferida pelo Estado com esse bem, que deverá ser usada, de certo, em benefício de toda a população brasileira; outra, bem diversa, é a possibilidade de uso direto desse bem.

\subsubsection{Do petróleo como bem de uso especial}

Durante o julgamento da ADIn 3.273-9/DF, os Ministros Marco Aurélio e Carlos Brito manifestaram-se no sentido de que o petróleo teria natureza de bem público de uso especial, sob o argumento de que o Estado não poderia dele dispor ao seu livre-arbítrio, por estar afetado a finalidades públicas, tais como: 1) atender às necessidades do consumo interno e 2) por ser um bem estratégico, que visa proteger o interesse nacional.

Ao expor seu posicionamento, o Ministro Marco Aurélio explicou que:

Ora, classificar o petróleo como bem público dominical significaria dizer que a Uniáo poderia dispor dessa propriedade sempre que bem entendesse, ou ainda, que poderia aliená-la sempre que desejasse, observados necessariamente os requisitos previstos em lei. Esse não é o alcance fidedigno da Carta de 1988, que a todos submete.

Da leitura da cabeça do artigo 173 da Constituição Federal, depreende-se que a exploração direta da atividade econômica pelo Estado somente pode ocorrer quando for necessária aos imperativos da segurança nacional ou de relevante interesse coletivo. E o monopólio da União, previsto no artigo 177, foi estabelecido justamente para obedecer a tais ditames de preservação do interesse público e da soberania nacional. Pode-se afirmar, sem contestação, com um mínimo de honestidade intelectual, que o petróleo é um bem público que possui destinação específica. A propriedade desse minério, garantida pelo regime de monopólio, visa exatamente a proteger o interesse coletivo e a soberania nacional. Essa é a destinação pública a que a propriedade do petróleo está sujeita.

E mais: de acordo com o inciso I do parágrafo $2^{\circ}$ do artigo 177 , a lei que estipular condiçōes por meio das quais a União poderá contratar com empresas privadas deverá obrigatoriamente determinar a garantia do fornecimento dos derivados de petróleo em território nacional. Em outras palavras, independentemente da natureza jurídica do contrato estabelecido, ou dos termos em que ocorrerá a participação da empresa privada, o contrato deverá conter, necessariamente, uma cláusula mediante a qual se assegure o fornecimento dos derivados de petróleo em todo o território nacional. 
Tal garantia, sem dúvida, constitui limitação ao livre exercício da propriedade do petróleo, que não poderá ser alienado por mera disponibilidade de vontade da Administração Pública, ou seja, ele não poderá ser exportado ou vendido a particulares sem que se tenha preservado o abastecimento interno (grifos nossos).

Posicionando-se também pela natureza do petróleo como bem de uso especial, o Professor Gilberto Bercovici afirma que "o petróleo e os recursos minerais são bens públicos de uso especial, bens indisponíveis cuja destinação pública está definida constitucionalmente: a exploração e o aproveitamento de seus potenciais" (2011, p. 289). Para ele, a exploração do petróleo e dos recursos minerais "está vinculada aos objetivos fundamentais dos artigos 3o 170 e 219 da Constituição de 1988, ou seja, o desenvolvimento, a redução das desigualdades e a garantia da soberania econômica nacional" (2011, p. 290). Por estar adstrito a tais objetivos ou finalidades específicas de ordem pública, é que se caracterizaria o petróleo como bem de uso especial, sendo, nas palavras do autor, "um patrimônio irrenunciável" (2011, p. 290).

Ao final, diz ainda que a transferência da propriedade do petróleo do Estado para o particular seria inconstitucional, aduzindo que "com a atribuição da propriedade do produto da lavra do petróleo e gás natural ao concessionário, o controle da atividade petrolífera deixa, concretamente, de ser monopólio da União, o que viola os artigos 20, IX, e 177 da Constituição de 1988” (2011, p. 296).

Perceba-se que o principal argumento utilizado pelos juristas para enquadrar o petróleo como bem de uso especial foi o fato de ele consubstanciar relevante interesse coletivo, pontificado na necessidade de abastecimento interno, na sua importância para o desenvolvimento do país, na redução das desigualdades, bem como para a garantia da soberania econômica nacional. Posicionam-se desta maneira, pois, para esta corrente a classificação do petróleo como um bem dominical lhe retiraria a possibilidade de conter tais finalidades, além de autorizar a Administração Pública a dele dispor ao seu livre arbítrio.

Discorda-se de tal entendimento por dois motivos. Primeiramente, a) não há como negar o atributo da alienabilidade a que está sujeito o petróleo no sistema jurídico atual, o que por si só o caracteriza como bem público dominical, pois, como visto, bens de uso especial são inalienáveis por estarem sujeitos ao uso direto ou indireto do poder público. Em segundo lugar, b) o fato de um bem ser classificado como dominical não implica, de maneira alguma, que ele não possa ser utilizado com vistas a atender a interesses nacionais, como de fato ocorre com o petróleo, que, como será visto, até mesmo após a sua alienação ao particular, continua sujeito ao cumprimento de finalidades públicas.

Com base em cada uma das razões expostas, passa-se a caracterizar o petróleo como bem dominical. 


\subsubsection{Da caracterização do petróleo como bem dominical.}

\section{Motivo 1: o atributo da alienabilidade}

Sem dúvida, é a potencial alienação a que está sujeito o petróleo que o caracteriza como bem dominical. Esta (a alienabilidade) é a característica que o diferencia dos bens de uso comum do povo e de uso especial, que até podem sofrer avaliação econômica, porém se encontram sob o uso direto ou indireto da Administração, motivo pelo qual não podem ser alienados sem que haja ato prévio de desafetação.

Ao se contrapor à tese defendida pelos Ministros Marco Aurélio e Carlos Brito, Eros Grau afirmou categoricamente em seu voto:

O tratamento da matéria reclama, além da prudência de sempre, a consideração de conceitos indispensáveis a sua compreensão e a prévia superação de alguns equívocos.

Primeiro desses equívocos: o petróleo seria bem público especial [não dominical, de uso comum da União e de uso especial por empresas particulares

É surpreendente que um mesmo bem público especial possa ser, concomitantemente, bem de uso comum da União e bem de uso especial por empresas particulares...

Além disso, se fosse bem de uso especial, o petróleo - como todos os bens de uso comum e de uso especial - seria inalienável enquanto conservasse essa qualificação, isto é, enquanto afetado a sua destinação; apenas poderia ser alienado ao ser desafetado. Como o que o caracterizaria como de uso especial seria a proteção do interesse coletivo e da soberania nacional, a sua desafetação implicaria precisamente que ele já não se prestasse a prover essa proteção... A concepção do petróleo como bem de uso especial conduz à conclusão lógica, porém literalmente incompreensível, de que o petróleo é inalienável. Nada mais é necessário dizer neste apartado (grifos nossos).

As lições de Eros Grau clarificam o quão incoerente é o entendimento que caracteriza o petróleo como bem público de uso especial. De fato, é absurdo pensar em um Estado que, beneficiado pela natureza com fartas jazidas de petróleo, seria impedido de aliená-lo, em virtude de o seu ordenamento jurídico concebê-lo como bem de uso especial. Afinal, mantido ad eternum embaixo da terra, de nada poderá contribuir para promover a melhoria dos serviços públicos ou a redução das desigualdades sociais e regionais, pois não é o recurso em si capaz de atender a tais propósitos, mas sim a receita pública auferida com a sua alienação.

O próprio Hely Lopes Meirelles, citado no voto proferido pelo Ministro Marco Aurélio, destaca a alienabilidade como característica essencial dos bens dominicais:

Bens dominiais, ou do patrimônio disponível, são aqueles que embora integrando o patrimônio público como os demais, deles diferem pela possibilidade sempre presente de serem utilizados em qualquer fim, ou mesmo alienados pela Administração se 
assim o desejar. Daí porque recebem também a denominação de bens patrimoniais disponíveis, ou de bens do patrimônio fiscal. Tais bens integram o patrimônio do Estado como objeto de direito real ou pessoal, isto é, sobre eles a Administração exerce poderes de proprietário, segundo os preceitos de direito constitucional e administrativo, na autorizada expressão de Clóvis Beviláqua (2007, p. 433, grifos nossos).$^{15}$

Ao tentar justificar a possibilidade de o Estado auferir renda com a venda do petróleo - que ainda assim seria um bem de uso especial em sua visão -, o Ministro Marco Aurélio afirma que nessa situação ocorreria um uso extraordinário ${ }^{16}$ de bem de uso especial, de modo que seria possível, neste caso, haver alienação de bem de uso especial, uma vez que se estaria diante de um "uso extraordinário do mesmo".

É necessário fazer ainda uma distinção quanto à utilização dos bens públicos, se de uso comum ou de uso especial - classificação que não se confunde com a dos próprios bens (de uso comum, dominicais ou especiais).

O uso dos bens públicos será comum, ou ordinário, quando observados os fins inicialmente previstos, de acordo com os objetivos e a destinação primeira. Como exemplo, tem-se o uso das vias para tráfego de veículos, ou de universidades para aulas e palestras.

De outra maneira, a utilização dos bens públicos poderá ser especial, ou seja, quando a aplicação do bem fugir àquela finalidade propedêutica, em casos em que houver alteração no destino final do bem. (...)

A possibilidade de se empregar um bem público estratégico para fins de exploração econômica, obtendo vultosos lucros, enquadra-se na modalidade de uso especial. Eis a razão porque deverá haver um contrato, por meio do qual a Administração Pública manifestará expressa concordância com a exploração econômica do bem público por terceiros, para atender também a fins particulares, tendo ainda de ser precedido de licitação, em obediência à moralidade e à impessoalidade que devem pautar as atividades do Governo.

Assim, conclui-se que o petróleo é um bem público especial, a ser explorado pela União diretamente - caso de uso comum - ou por empresas particulares - hipótese de uso especial.

$15 \mathrm{O}$ fato de o autor aduzir que os bens dominicais podem ser utilizados em qualquer fim deve ser entendido nos seguintes termos: utilizados em qualquer fim de interesse público. É certo que a possibilidade de se atribuir diversas finalidades (sempre de interesse público) aos bens dominicais não quer dizer que em relação a estes se possa falar em ausência de finalidade. Comportar finalidades múltiplas é diferente de não comportar finalidade alguma, mesmo porque sempre estará presente o interesse público, ainda que este se consubstancie na mera administração do bem, com vistas a auferir renda, conforme bem exposto por Di Pietro: "a própria administração financeira constitui objetivo apenas imediato, pois, em uma perspectiva mais ampla, atende a fins de interesse geral" (2011, p. 679).

16 Prefere-se utilizar a expressão extraordinário, também corrente na doutrina, em oposição ao uso ordinário dos bens públicos, para evitar a repetição do vocábulo especial. 
Com vistas a analisar o exposto no excerto, eis as lições de Edmir Netto de Araújo acerca do uso normal e anormal de bem público, referidos no voto como uso comum e especial:

Independentemente das noções de uso comum pelo povo ou privativo por particulares, tem-se que o uso normal de bens públicos é aquele que acontece de acordo com a destinação do bem. Pode portanto ser uso normal pela própria Administração (como utilização de um bem destinado a um serviço público, p. ex.), uso comum normal (como a utilização de uma rua para trânsito da população, p. ex), ou uso privativo normal (como a utilização por particular de um bem objeto de concessão ou permissão de uso).

Já o uso anormal pode ser desempenhado pela própria Administração (utilizar emergencialmente como pista de pouso de aeronave um bem destinado, p. ex., a um assentamento), pode se constituir em uso comum anormal (desfiles, passeatas autorizadas em vias públicas) ou uso privativo anormal (autorização de colocação de mesas e cadeiras na calçada em frente a um bar), em qualquer caso não podendo ser incompatível com o uso normal (2010, p. 1.148).

Explorar o petróleo com vistas a auferir renda não pode ser visto como uso anormal ou extraordinário desse recurso, ainda quando tal atividade seja desempenhada diretamente pelo Estado. Se apenas o seu emprego para atender a finalidades estratégicas caracterizaria o seu uso normal, quando então isso ocorreria? Em caso de guerra? Até lá, o seu uso normal seria o seu não uso, isto é, a sua manutenção embaixo da terra para servir de reserva energética em caso de uma situação extrema de necessidade de abastecimento? Acredita-se que não. A preservação de jazidas a título de contingência para situações desse tipo, de fato, mostra-se de extrema relevância para a segurança nacional, o que se julga ser uma política cuja efetivação merecia ser discutida pelo Congresso Nacional. No entanto, a utilização do petróleo para este fim, aí sim, caracterizaria o uso extraordinário desse recurso, que, hodiernamente, é comercializado por aqueles que o produzem com vistas a auferir renda, em sua maior parte para refinarias destinadas a transformá-lo em diferentes espécies de derivados.

\subsubsection{Da caracterização do petróleo como bem dominical. Motivo 2: permanência do interesse coletivo antes, durante e após a sua alienação ao particular}

Como bem expôs Maria Sylvia Zanella Di Pietro, citada anteriormente, quando se tratou das características que informam os bens dominicais, não é por serem passíveis de disposição que deixam de cumprir finalidades públicas, podendo o Estado regular o seu uso, mesmo quando feito pelo particular, com vistas a atender a objetivos de interesse coletivo. 
Para os Ministros Marco Aurélio e Carlos Brito, bem como para Bercovici, o fato de o petróleo destinar-se a atender a finalidades públicas, além de ser um bem essencial à soberania brasileira, faz dele um bem de uso especial. De que o petróleo é um bem essencial à soberania, certamente, não se discorda; no entanto, a questão merece ser analisada por um outro ângulo.

Conforme visto no Capítulo 1, soberania e propriedade são conceitos distintos. Isso quer dizer que um Estado exerce plenamente sua soberania sobre os recursos naturais presentes no seu território, mesmo quando atribua direitos de propriedade sobre estes a particulares, estejam tais recursos ainda no subsolo (como ocorre nos Estados Unidos), ou após terem sido explotados.

O que de fato caracteriza a soberania de um Estado sobre seus recursos naturais é a sua liberdade para definir o que se entende por propriedade, quem tem a propriedade dos recursos naturais, e em que condiçôes. Some-se a isso a possibilidade sempre presente, conforme disposto no artigo $4^{\circ}$ da Resolução n. 1.803 da ONU, de o Estado proceder à nacionalização, expropriação ou requisição das áreas concedidas, quando existam razões de utilidade pública, segurança, ou interesse nacional que justifiquem a medida, devendo efetuar o pagamento de justa indenização. Essa previsão mostra-se necessária, tendo em vista que pode ocorrer de um governo firmar contrato para a exploração e produção de petróleo com companhia privada, que após alguns anos se mostre claramente desvantajoso afinal, governos, bons e maus, passam, mas o Estado permanece. Diante disso, havendo novos representantes no exercício do poder desse Estado, devem eles ter ao seu dispor medidas jurídicas aptas a rever as condições do contrato, ou mesmo revogá-lo.

Lembra-se também que para que o Estado decida sobre as condições do exercício da propriedade do petróleo, não é necessário que seja o proprietário dos recursos, podendo fazê-lo por meio de regulação, como de fato faz o Estado brasileiro - e o faz de maneira bastante incisiva, diga-se.

A indústria petrolífera no Brasil é uma das mais fortemente reguladas, tendo o ente público total liberdade para decidir quando, quais e com que periodicidade serão licitados blocos para exploração e eventual produção, além de ter à sua disposição uma série de mecanismos de controle tanto da produção como da comercialização do bem em questão.

No que tange ao controle do nível de produção de petróleo por uma empresa, isto é feito no Brasil mediante a necessidade da contratada, após declarar a comercialidade de um campo, estar obrigada, por força dos artigos 26 e 44 da Lei do 
Petróleo, ${ }^{17}$ e dos artigos 11 e $29^{18}$ da Lei n. 12.351 (Lei do Contrato de Partilha), a apresentar um plano de desenvolvimento, por meio do qual devem ser fornecidas informações detalhadas sobre a tecnologia utilizada para o desenvolvimento dos poços, bem como o ritmo de produção, além de uma série de outras informações técnicas enumeradas na Portaria ANP n. 90/2000, estando tal documento sujeito à aprovação da Agência Nacional de Petróleo.

Além disso, a empresa contratada deverá, ano a ano, conforme cláusula contida no Contrato de Concessão para a Décima Rodada de Licitações, apresentar um programa anual de produção, também sujeito à aprovação da ANP, onde deve

Art. 26. A concessão implica, para o concessionário, a obrigação de explorar, por sua conta e risco e, em caso de êxito, produzir petróleo ou gás natural em determinado bloco, conferindo-lhe a propriedade desses bens, depois de extraídos, com os encargos relativos ao pagamento dos tributos incidentes e das participações legais ou contratuais correspondentes. (...)

$\$ 1^{\circ}$ Em caso de êxito na exploração, o concessionário submeterá à aprovação da ANP os planos e projetos de desenvolvimento e produção (grifos nossos).

Art. 44. O contrato estabelecerá que o concessionário estará obrigado a:

I - adotar, em todas as suas operações, as medidas necessárias para a conservação dos reservatórios e de outros recursos naturais, para a segurança das pessoas e dos equipamentos e para a proteção do meio ambiente;

II - comunicar à ANP, imediatamente, a descoberta de qualquer jazida de petróleo, gás natural ou outros hidrocarbonetos ou de outros minerais;

III - realizar a avaliação da descoberta nos termos do programa submetido à ANP, apresentando relatório de comercialidade e declarando seu interesse no desenvolvimento do campo;

IV - submeter à ANP o plano de desenvolvimento de campo declarado comercial, contendo o cronograma e a estimativa de investimento;

$\mathrm{V}$ - responsabilizar-se civilmente pelos atos de seus prepostos e indenizar todos e quaisquer danos decorrentes das atividades de exploração, desenvolvimento e produção contratadas, devendo ressarcir à ANP ou à União os ônus que venham a suportar em consequência de eventuais demandas motivadas por atos de responsabilidade do concessionário;

VI - adotar as melhores práticas da indústria internacional do petróleo e obedecer às normas e procedimentos técnicos e científicos pertinentes, inclusive quanto às técnicas apropriadas de recuperação, objetivando a racionalizaçáo da produção e o controle do declínio das reservas (grifos nossos).

Art. 11. Caberá à ANP, entre outras competências definidas em lei: (...)

IV - fazer cumprir as melhores práticas da indústria do petróleo;

$\mathrm{V}$ - analisar e aprovar, de acordo com o disposto no inciso IV deste artigo, os planos de exploração, de avaliação e de desenvolvimento da produção, bem como os programas anuais de trabalho e de produção relativos aos contratos de partilha de produção; e

Art. 29. São cláusulas essenciais do contrato de partilha de produção: (...) XIII - os critérios para formulação e revisão dos planos de exploração e de desenvolvimento da produção, bem como dos respectivos planos de trabalho, incluindo os pontos de medição e de partilha de petróleo, de gás natural e de outros hidrocarbonetos fluidos produzidos; 
constar o ritmo de produção para o ano subsequente, em consonância com o que fora apresentado anteriormente no plano de desenvolvimento. ${ }^{19}$

Quanto à obrigatoriedade de assegurar o abastecimento nacional, tal mandamento encontra-se positivado em uma série de diplomas normativos. Primeiramente, na Constituição Federal e na Lei do Petróleo (Lei n. 9.478/97). De maneira mais concreta, na Lei n. 8.176/91, a qual instituiu o Sistema Nacional de Estoques de Combustíveis e determinou, em seu artigo 4º, a elaboração de um Plano Anual de Estoques Estratégicos de Combustíveis, pelo Conselho Nacional de Política Energética, competência esta que lhe foi atribuída por meio do Decreto $n$. 3.520/2000, em seu artigo 1\%, V. Como se não bastasse, também no Contrato de Concessão para a Exploração e Produção de Petróleo e Gás, na cláusula décima primeira, que versa sobre medição, entrega e disponibilidade da produção, impõe-se ao contratado a obrigatoriedade de assegurar o abastecimento nacional em caso de emergência nacional, nos seguintes termos:

11.5 Se, em caso de emergência nacional, que possa colocar em risco o fornecimento de petróleo ou gás natural no território nacional declarada pelo Presidente da República ou pelo Congresso Nacional, houver necessidade de limitar exportaçōes de Petróleo ou Gás Natural, a ANP poderá, mediante notificação por escrito com antecedência de 30 (trinta) dias, determinar que o Concessionário atenda, com Petróleo e Gás Natural por ele produzidos e recebidos nos termos deste Contrato, às necessidades do mercado interno ou de composição dos estoques estratégicos do País. A participação do Concessionário será feita, em cada mês, na proporção de sua participação na Produção nacional de Petróleo e Gás Natural do mês anterior.

19 Programa Anual de Produção

10.2 No máximo até o dia 31 de outubro de cada ano civil, o Concessionário entregará à ANP, para cada Campo, o Programa Anual de Produção do ano subsequente, de acordo com o Plano de Desenvolvimento para o Campo, a legislação brasileira aplicável e as Melhores Práticas da Indústria do Petróleo. O Programa Anual de Produção conterá ainda as explicações cabíveis, sempre que o total anual da Produção nele indicado sofrer uma variação igual ou maior do que $10 \%$ (dez por cento), quando comparado com o total anual respectivo previsto no Plano de Desenvolvimento em vigor aplicável ao Campo.

10.6 A ANP terá o prazo de 30 (trinta) dias, contados do recebimento do Programa de Produção, para solicitar ao Concessionário quaisquer modificações que julgar cabíveis, sempre que esse Programa de Produção não atender às disposiçôes do parágrafo 10.2. Caso a ANP solicite tais modificações, o Concessionário terá 30 (trinta) dias contados da data da referida solicitação, para discuti-las com a ANP e reapresentar o Programa de Produção com as modificações acordadas. Observado o disposto no parágrafo 8.9, o Concessionário estará obrigado a cumprir o Programa de Produção submetido à ANP, com as modificações que possam ter sido determinadas pela mesma, conforme aqui previsto, aplicando a estas modificaçóes o procedimento previsto neste parágrafo 10.6, observado ainda o disposto no parágrafo 10.9. 
Como se percebe, apesar de ser um bem dominical, sujeito a alienação ao particular, a preservação do interesse coletivo neste bem está assegurada por meio de instrumentos normativos, submetendo-se o petróleo a uma forte regulação, mesmo após a sua propriedade ter sido transferida ao particular, característica essa decorrente do poder soberano do Estado sobre seus recursos naturais, que se mantém, resguardando o interesse coletivo nesse bem. 
